\title{
The clinical efficacy of arthroscopic therapy with knee infrapatellar fat pad cell concentrates in treating knee cartilage lesion: a prospective, randomized, and controlled study
}

Yiqin Zhou ${ }^{\dagger}$, Haobo Li ${ }^{\dagger}$, Dong Xiang ${ }^{\dagger}$, Jiahua Shao, Qiwei Fu, Yaguang Han, Jun Zhü ${ }^{*+}$, Yi Chen $^{*+}$ and Qirong Qian ${ }^{*+}$

\begin{abstract}
Introduction: To evaluate the clinical efficacy of arthroscopic therapy with infrapatellar fat pad cell concentrates in treating knee cartilage lesions, we conducted a prospective randomized single-blind clinical study of controlled method.

Methods: Sixty cases from Shanghai Changzheng Hospital from April 2018 to December 2019 were chosen and randomly divided into 2 groups equally. Patients in the experiment group were treated through knee arthroscopy with knee infrapatellar fat pad cell concentrates containing mesenchymal stromal cells, while patients in the control group were treated through regular knee arthroscopic therapy. VAS and WOMAC scores were assessed at preoperation, and 6 weeks, 12 weeks, 6 months, and 12 months after intervention. MORCART scores were assessed at pre-operation and 12 months after intervention.

Results: Twenty-nine cases in the experiment group and 28 cases in the control group were followed up. No significant difference in VAS, WOMAC, and MOCART scores were found between the two groups before surgery $(P$ $>0.05)$. The WOMAC total and WOMAC function scores of the experiment group were significantly lower than those of the control group 6 months and 12 months after surgery $(P<0.05)$. The VAS rest and VAS motion scores of the experiment group were found significantly lower than those of the control group 12 months after surgery $(P<$ 0.05). The MOCART scores of the experiment group were found significantly higher compared with the control group 12 months after surgery $(P<0.05)$. No significant difference in WOMAC stiffness scores were found between the two groups.
\end{abstract}

Conclusions: The short-term results of our study are encouraging and demonstrate that knee arthroscopy with (Continued on next page)

\footnotetext{
*Correspondence: arthrozhujun@sina.com; lother@163.com; qianqr@163.com

'Yiqin Zhou, Haobo Li, and Dong Xiang contributed equally to this work and should be considered as co-first authors.

Department of Joint Surgery and Sports Medicine, Shanghai Changzheng Hospital, Naval Medical University, No.415 Fengyang Road, Shanghai 200003, China
}

(c) The Author(s). 2021 Open Access This article is licensed under a Creative Commons Attribution 4.0 International License, which permits use, sharing, adaptation, distribution and reproduction in any medium or format, as long as you give appropriate credit to the original author(s) and the source, provide a link to the Creative Commons licence, and indicate if changes were made. The images or other third party material in this article are included in the article's Creative Commons licence, unless indicated otherwise in a credit line to the material. If material is not included in the article's Creative Commons licence and your intended use is not permitted by statutory regulation or exceeds the permitted use, you will need to obtain permission directly from the copyright holder. To view a copy of this licence, visit http://creativecommons.org/licenses/by/4.0/. The Creative Commons Public Domain Dedication waiver (http://creativecommons.org/publicdomain/zero/1.0/) applies to the data made available in this article, unless otherwise stated in a credit line to the data. 


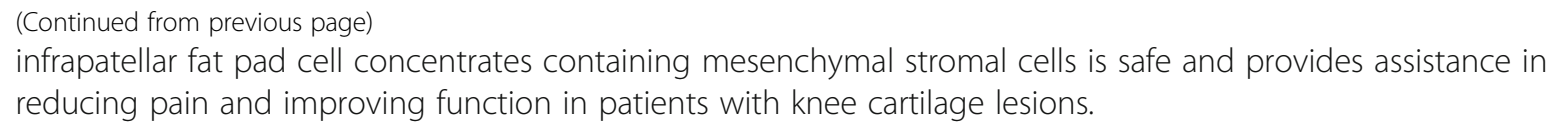

Keywords: Knee cartilage lesion, Randomized controlled trial, Infrapatellar fat pad adipose tissue, Mesenchymal stromal cells, Cartilage regeneration

\section{Introduction}

Articular cartilage lesions of the knee are extremely common, with a high morbidity rate of $5 \%$ in the general population and $22-50 \%$ in the athlete population $[1,2]$. They can be caused by trauma, malalignment in the load-bearing axis, and aging. Currently, traditional clinical therapies for knee cartilage lesions include drug therapy (with glucosamine, for example), simple arthroscopic debridement, microfracture surgery, and autologous osteochondral transplantation [3-7]. However, the therapeutic efficacy of drug therapy and simple arthroscopic debridement is limited [1]. In addition, the utility of the microfracture technique is confined to the treatment of small-scale damage, and the use of autologous osteochondral transplantation is limited by an insufficient donor supply [7-10]. Currently, these known therapies can be effective for a short period, but their longterm efficacies are uncertain $[11,12]$.

Recently, cartilage tissue engineering based on mesenchymal stromal cells (MSCs) has become an effective treatment choice [12-14]. MSCs are a kind of multipotent stromal cells, which may have potential as a treatment option for early cartilage lesions. The infrapatellar fat pad (IPFP), routinely removed in knee arthroscopic surgery, is a good source of MSCs. Compared with other tissues, the use of the IPFP, which is a waste source in regular knee arthroscopy surgery, can result in less damage to the donor zone and offer more MSCs with differentiative capacity [15-22].

Stromal cell therapy, which can be categorized into pure cell and cell concentrate therapies [21], is still being investigated in clinical trials. Compared with pure cell therapy, treatment with cell concentrates containing stromal cells takes less time in the cell isolating procedure and can be more expediently $[19,20]$. In our study, we conducted a randomized controlled trial to evaluate whether knee arthroscopic therapy with IPFP cell concentrates containing MSCs is safe and can improve clinical symptoms of patients with knee cartilage lesions.

\section{Methods}

\section{Trial design}

This study is a randomized controlled trial of Evidence Level I from April 2018 to December 2019. The study conforms to the principles of the Declaration of Helsinki. The trial is endorsed by the Shanghai Changzheng Hospital Ethics Committee (CZEC (2016)-02). There is no commercial sponsorship of this study. The trial is registered (ChiCTR1800015379).

\section{Trial participants}

All participants learned about research recruitment from outpatient surgeons. To be admitted to the trial, the inclusion criteria for patients were (1) age between 18 and 75 years old, (2) presence of clearly indicated articular cartilage lesions on MRI and Kellgren-Lawrence grade $\leq$ level 3, (3) obvious knee pain or discomfort lasting for more than 3 months, (4) understanding of the treatment and signed informed consent by the patient or their family, (5) articular cartilage lesions diagnosed by arthroscopy without targeted treatment.

The exclusion criteria for patients were (1) previous surgical procedures for articular cartilage lesions, (2) history of intra-articular injection or history of periarticular invasive treatments within 3 months of the start of the study, (3) symptoms and imaging findings localized in the patellofemoral joint, (4) presence of malignant neoplasms, (5) active infection anywhere in the body, (6) pregnant or lactating women or women preparing for pregnancy, (7) articular cartilage lesions caused by infectious or gouty arthritis, (8) presence of autoimmune diseases such as rheumatoid arthritis or ankylosing spondylitis, (9) diabetes with fasting blood glucose over $8 \mathrm{mmol} / \mathrm{L}$, (10) general poor health and not recommended for surgery, (11) presence of severe diseases such as cerebral hemorrhage, severe pneumonia, or multiple organ dysfunction, (12) failure to give consent to participate in the study, (13) diagnosis of Charcot joint, (14) findings that may increase patient risk or influence the results of the intervention, (15) other reasons for not being fit for the study.

After being advised about the trial protocol and prior to the start, all patients submitted written informed consent.

\section{Randomization and blinding}

Randomization was performed by an independent researcher not involved in the treatment or outcome 
measurement. After providing informed consent, each eligible patient was randomly assigned a sequence number from a computer-generated random number list and randomly separated into one of the two study groups: an experiment group (knee arthroscopic therapy with autologous IPFP cell concentrates) or a control group (knee arthroscopic therapy only). The random number was concealed in a sealed envelope and saved by a researcher who did not participate in the trial. The final unblinding was performed after data collection. Participants were kept blinded to the allocated treatment during the follow-up period. All participants in the experiment group and control group received knee arthroscopic therapy by the same surgeon. Outcome assessors were blinded to the study groups and did not take part in the implementing interventions. During follow-up, all the doctors, radiologists, and statisticians were unaware of the study group assignments.

\section{Interventions}

\section{Experiment group}

All participants in the experiment group received knee arthroscopic therapy by the same surgeon. All the interventions were done in the laminar flow operation room, which was in aseptic condition. After total anesthesia, the surgeon evaluated the medial, lateral, and patellofemoral joint compartments. Then, the surgeon performed one or more of the following treatments: debridement; excision of degenerative tears of the menisci, fragments of articular cartilage, chondral flaps, or osteophytes that prevented full extension. Neither abrasion nor microfracture of cartilage lesion was performed. During the knee arthroscopic therapy, partial IPFP tissue was acquired using a standard motorized shaver system. Briefly, $200 \mathrm{~mL}$ of the mixture containing fat, synovial tissue, and $0.9 \%$ saline was collected by a sterilized arthroscopic setup of the fat collection system connected with suction apparatus. After being filtered twice using a 30-mesh filter (pore size of $550 \mu \mathrm{m}$ ) to remove the synovial tissue, the mixture was centrifuged at $300 \times g$ for 5 min [23]. While the liquid supernatant was discarded, 6 $\mathrm{mL}$ of $0.9 \%$ saline was used to mix the lipoaspirate to make cell the concentrates. In total, $5 \mathrm{~mL}$ of the cell concentrates was injected into the corresponding joint cavity, and another $1 \mathrm{~mL}$ was used for identification by flow cytometry [23] and cultured to determine if the cell concentrates were contaminated (Fig. 1).

The cell concentrates were assayed for cell surface protein expression by flow cytometry (FC500, Beckman Coulter, USA). One hundred microliters from $1 \mathrm{~mL}$ of freshly isolated cell concentrates was washed twice with phosphate-buffered saline. The antibodies used for the identification of cell concentrates were CD45-FITC, CD44-PE-Cy, CD90-PE, and PE-CD105 (BD Pharmingen, USA). As a negative control, a cell suspension without antibodies was employed following the same

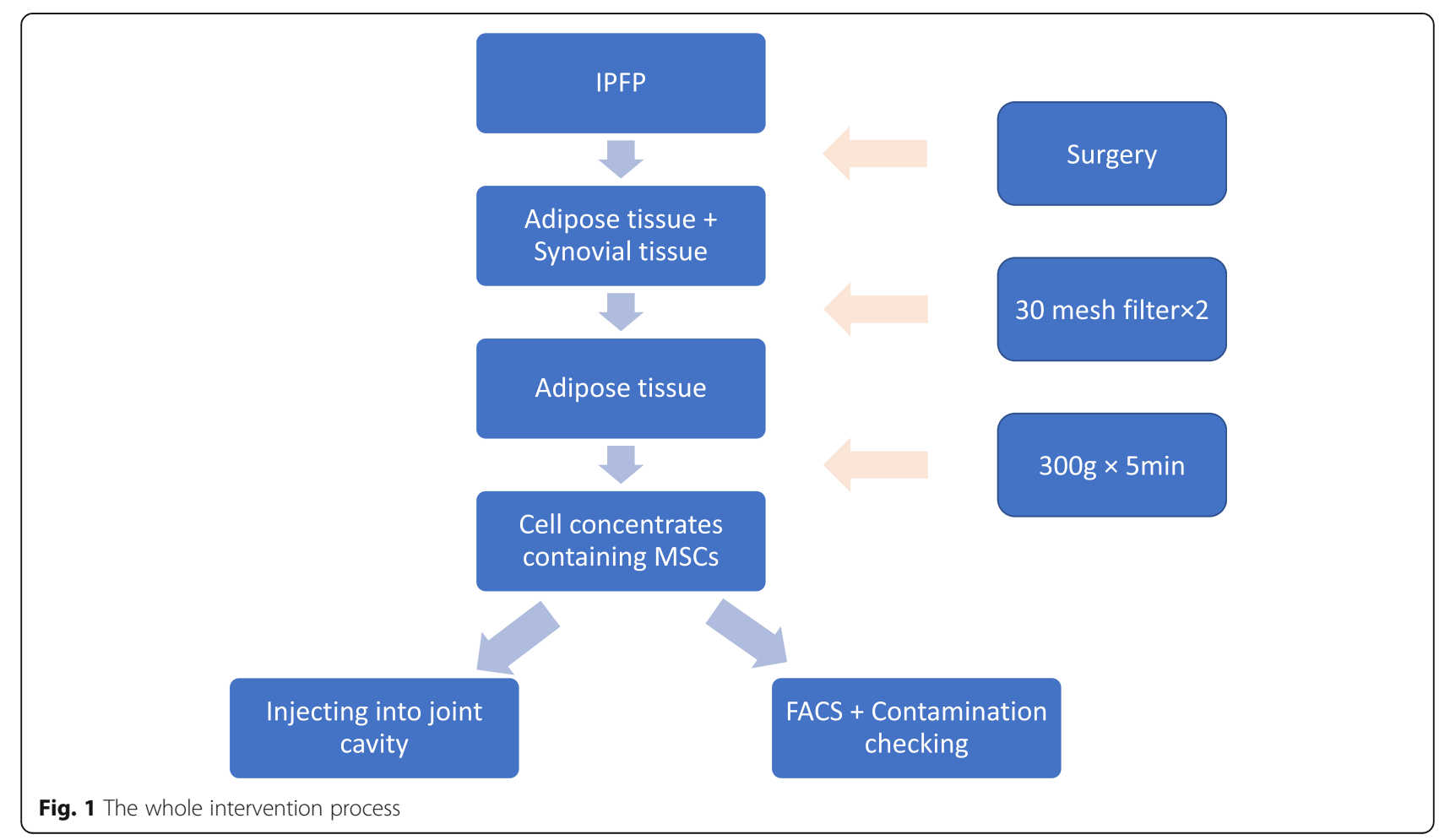


Table 1 Baseline characteristics of the patients

\begin{tabular}{llll}
\hline Characteristic & Experiment & Control & $\boldsymbol{P}$ values \\
\hline Cases (complete F-U) & $30(29)$ & $30(28)$ & \\
Age & $52.27 \pm 1.17$ & $51.77 \pm 7.55$ & $>0.05$ \\
Gender (M/F) & 5,25 & 8,22 & $>0.05$ \\
BMI (Kg/m $\left.{ }^{2}\right)$ & $24.19 \pm 2.54$ & $23.61 \pm 3.04$ & $>0.05$ \\
Kellgren-Lawrence grade & & & \\
$\quad 0$ & 5 & 4 & $>0.05$ \\
I & 5 & 7 & $>0.05$ \\
II & 17 & 16 & $>0.05$ \\
$\quad$ III & 3 & 3 & $>0.05$ \\
Type of disease & & & $>0.05$ \\
$\quad$ Simple knee cartilage lesion & 7 & 6 & $>0.05$ \\
$\quad$ Meniscus injury & 21 & 23 & $>0.05$ \\
$\quad$ Ligamentous injury & 2 & 1 &
\end{tabular}

procedure. Cell concentrates were incubated with antibodies for $20 \mathrm{~min}$ at $4{ }^{\circ} \mathrm{C}$ and then resuspended in fluorescence-activated cell-sorting media and analyzed immediately.

\section{Control group}

All participants in the control group received regular knee arthroscopic therapy after anesthesia. During the arthroscopic therapy, same amount of the IPFP tissue was removed under arthroscope; then, the joint cavity was treated with routine arthroscopic therapy same as the experiment group. After the arthroscopic therapy, $5 \mathrm{~mL}$ of $0.9 \%$ saline was injected into the treated knee cavity.

\section{Concomitant care and interventions}

Patients in both groups were restricted from taking corticosteroids and nonsteroidal anti-inflammatory drugs 1 week before surgery. After the surgery, no corticosteroid was injected into the knee articular cavity. During the rehabilitation period, walking and mild activities were not restricted. Subsequently, the gradual resumption of normal sports or recreational activities was allowed. No analgesics or anti-inflammatory drugs were allowed after the treatment. All post-operational treatment and rehabilitation processes were the same in both groups.

\section{Assessment}

All patients were evaluated by an investigator blinded to the group allocation. The Western Ontario and McMaster Universities Osteoarthritis Index (WOMAC) of patients were assessed preoperatively and at 6 weeks, 12 weeks, 6 months, and 12 months after the intervention to evaluate the functional recovery of the knee joint. The secondary objective of the study was to compare the efficacy of the two methods for pain relief using the visual analog scale (VAS) in both static and motion states at pre-operation and 6 weeks, 12 weeks, 6 months, and 12 months after the intervention. The safety of the two methods was assessed by routine blood analysis, hepatorenal function, and ESR and CRP levels at each follow-up.

Knee magnetic resonance imaging (MRI) was conducted to assess the cartilage regeneration at pre-

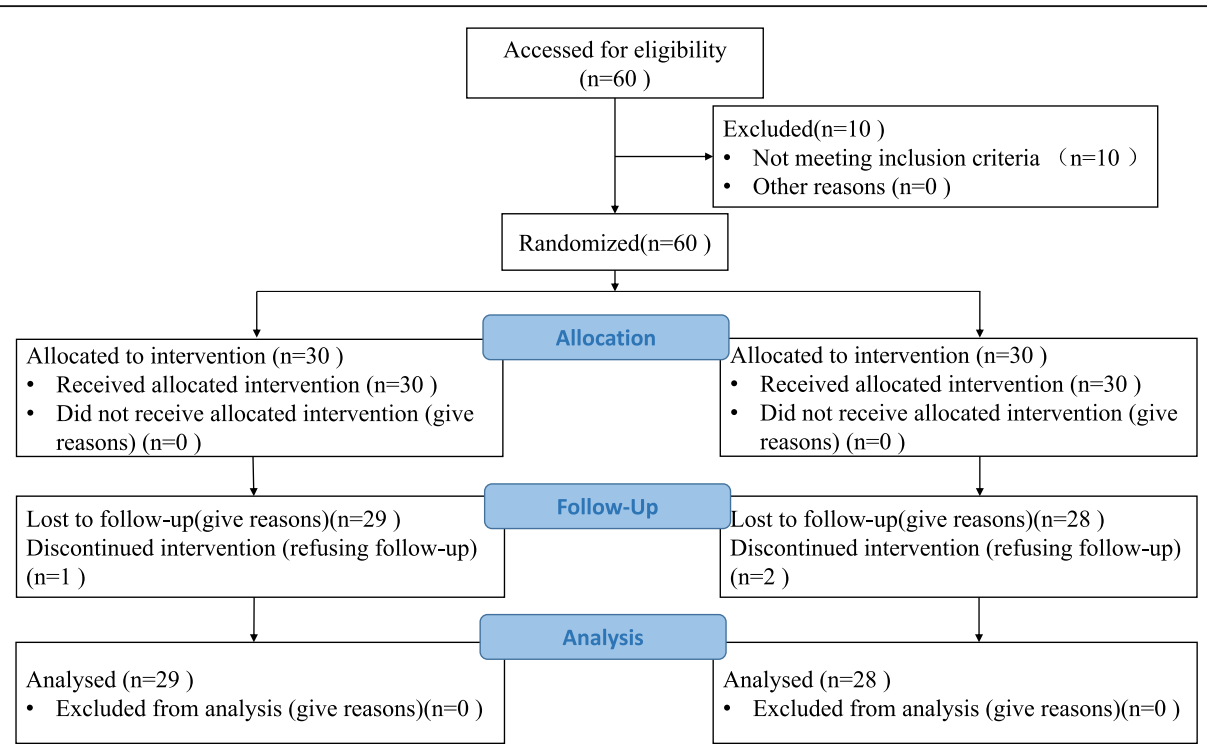

Fig. 2 The CONSORT flowchart diagram 


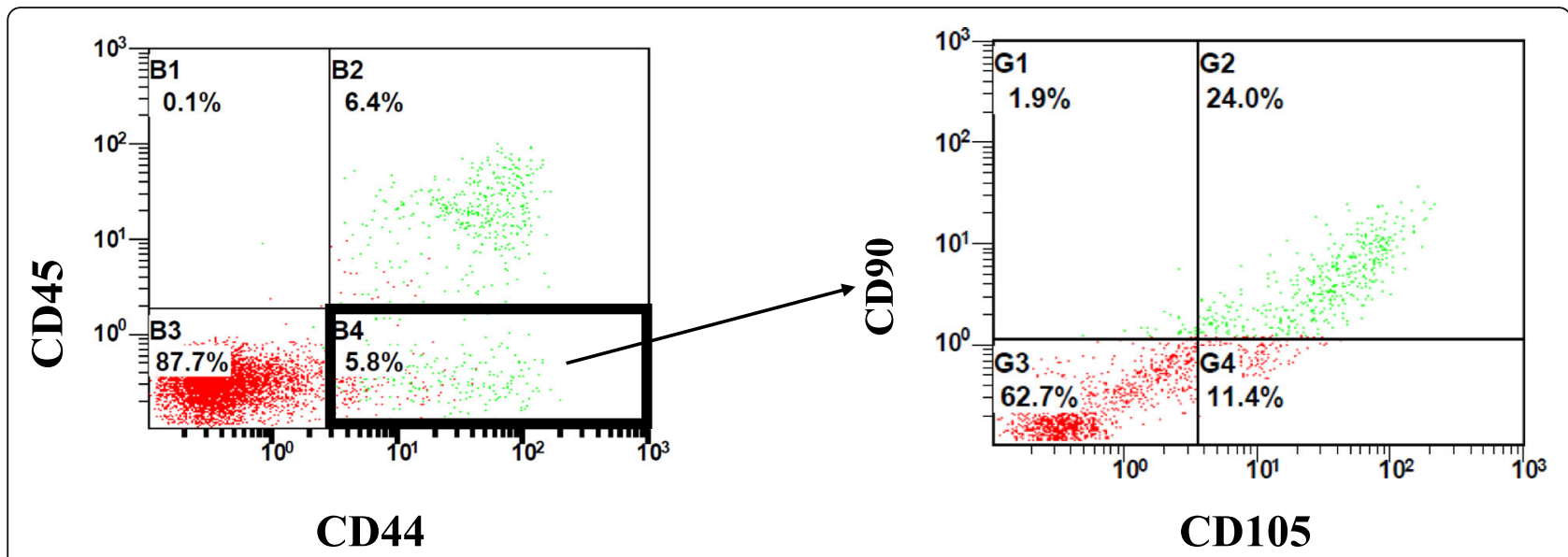

Fig. 3 Representative results from the fluorescence-activated cell sorting analysis of freshly isolated cell concentrates for (a) synovial markers $(\mathrm{CD} 45-\mathrm{CD} 44+)$ and (b) mesenchymal markers (CD90 + CD105+). The numbers represent the percentage of gated cells over live cells as the parental population

operation and 12 months after the intervention using Magnetic Resonance Observation of Cartilage Repair Tissue (MOCART). All these evaluations were performed by two well-experienced orthopedists; once disagreements existed, a third one would join in.

\section{Side effects}

Adverse reactions were defined as any unexpected events that occurred when the trial was noted and recorded. Serious adverse events (SAEs) were defined as events that were life-threatening or resulted in death, hospitalization, or significant disability.

\section{Statistical analysis}

All statistical analyses were performed with the SPSS software, version 19.0 (IBM, Armonk, NY). All data were expressed as means and standard deviations. Because the primary outcome was the difference in WOMAC score between baseline and 12 months, sample size was set based on the results of our pilot study and previous study [22] ( $\alpha$ risk 0.05 , power $0.8,10 \%$ losses to followup, changes in WOMAC score 15, and SD 8). The required number of patients should be at least 23. To improve the reliability of our study, we increased the sample size to 30 patients per group.The Student $t$ tests were used to analyze statistical differences between preoperative and follow-up values of WOMAC scores, VAS scores, and MOCART scores. For all the tests, significance was defined as $P<0.05$.

\section{Results}

A total of 30 cases were enrolled in each group. Twentynine cases in the experiment group and 28 cases in the control group were followed up (for patients data, see Table 1 and Fig. 2). According to the results of flow cytometry, $1.19 \pm 1.17 \times 10^{8}$ cells $/ \mathrm{ml}$ of cell concentrates in average were harvested from each patient, while 3.91 $\pm 2.96 \times 10^{6} \mathrm{cells} / \mathrm{ml}$ of cell concentrates in average were proved to be stromal cells $\left(\mathrm{CD} 45^{-} \mathrm{CD} 44^{+} \mathrm{CD} 90^{+} \mathrm{CD} 105^{+}\right)$, with a percentage of $4.38 \pm 2.29 \%$ in average (Fig. 3, Tables 2 and 3)

No significant difference of the average age of patients (52.27 years), VAS, and WOMAC scores were found between experiment group and control group before surgery $(P>0.05)$. WOMAC scores decreased substantially over the follow-up period (Fig. 4). The mean WOMAC total and WOMAC function scores of the experiment group were significantly lower than those of the control group 6 months and 12 months after surgery $(P<0.05)$ (Fig. 4a and d). The mean scores of WOMAC pain of the experiment group were only found significantly lower than those of the control group 12 months after surgery $(P<0.05)$ (Fig. 4b). As for the scores of stiffness, no significant difference was found between the two groups $(P>0.05)$ (Fig. 4c). In the aspect of VAS rest and VAS motion scores, significant decrease in the experiment group was found 12 months after surgery $(P<0.05)$ compared with the control group (Fig. 5). And MOCART scores of the experiment group were also found

Table 2 Arthroscopic harvest of cell concentrates from infrapatellar fat pad

\begin{tabular}{llll}
\hline & Total cells $\left(\times \mathbf{1 \mathbf { 1 } ^ { \mathbf { 8 } } )}\right.$ & Stem cells $\left(\times \mathbf{1 0 ^ { 6 }}\right)$ & Percentage $(\%)$ \\
\hline Cell concentrates & $1.19 \pm 1.17$ & $3.91 \pm 2.96$ & $4.38 \pm 2.29$ \\
\hline
\end{tabular}

Data are presented as mean \pm SD 
Table 3 Surface marker of cell concentrates by flow cytometric analysis

\begin{tabular}{ll}
\hline Markers & Percentage (\%) \\
\hline $\mathrm{CD} 45^{-}$ & $12.50 \pm 4.83$ \\
$\mathrm{CD}^{+} 4^{+}$ & $6.70 \pm 5.72$ \\
$\mathrm{CD}^{+}$ & $6.80 \pm 3.89$ \\
$\mathrm{CD}^{+} 5^{+}$ & $11.02 \pm 4.71$ \\
$\mathrm{CD} 45^{-} \mathrm{CD} 44^{+} \mathrm{CD} 90^{+} \mathrm{CD} 105^{+}$ & $4.38 \pm 2.29$ \\
\hline
\end{tabular}

Data are presented as mean \pm SD of the percentage of cells staining with antihuman mouse IgG antibodies

significantly higher than those of the control group 12 months after surgery $(P<0.05)$ (Figs. 6 and 7 ). During the follow-up period, no case of articular infection or damage to the hepatorenal function was found (Table 4).

\section{Discussion}

In this study, the short-term results are encouraging and demonstrate that knee arthroscopy with IPFP cell concentrates containing MSCs reduce pain and improve function in patients with knee cartilage lesions, especially at 6 and 12 months after surgery. In addition, no significant difference was found in the WOMAC and VAS scores in the early post-surgery stages between the two groups. This may be because the main effect of the MSCs in cell concentrates works to repair the lesion cartilage rather than reducing inflammation in the early postoperative stage $[12,24]$. With respect to safety, the therapy did not increase the probability of postoperative infection and had no obvious influence on the hepatic and renal function of patients.

Cartilage lesions have very limited intrinsic healing capacity. Surrounded by fewer vessels, nerves, and lymphoid tissue, cartilage with large lesions undergo repair only

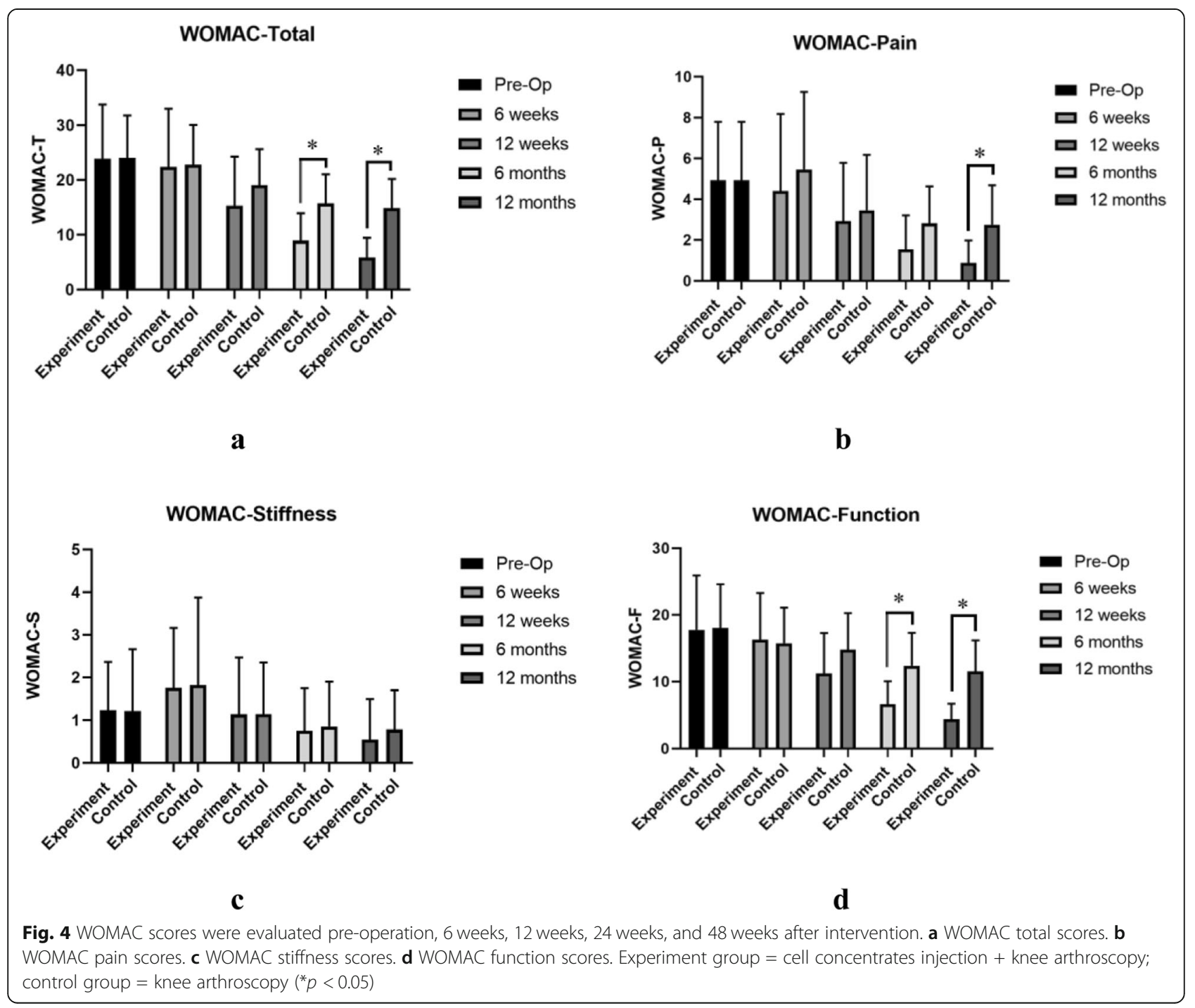




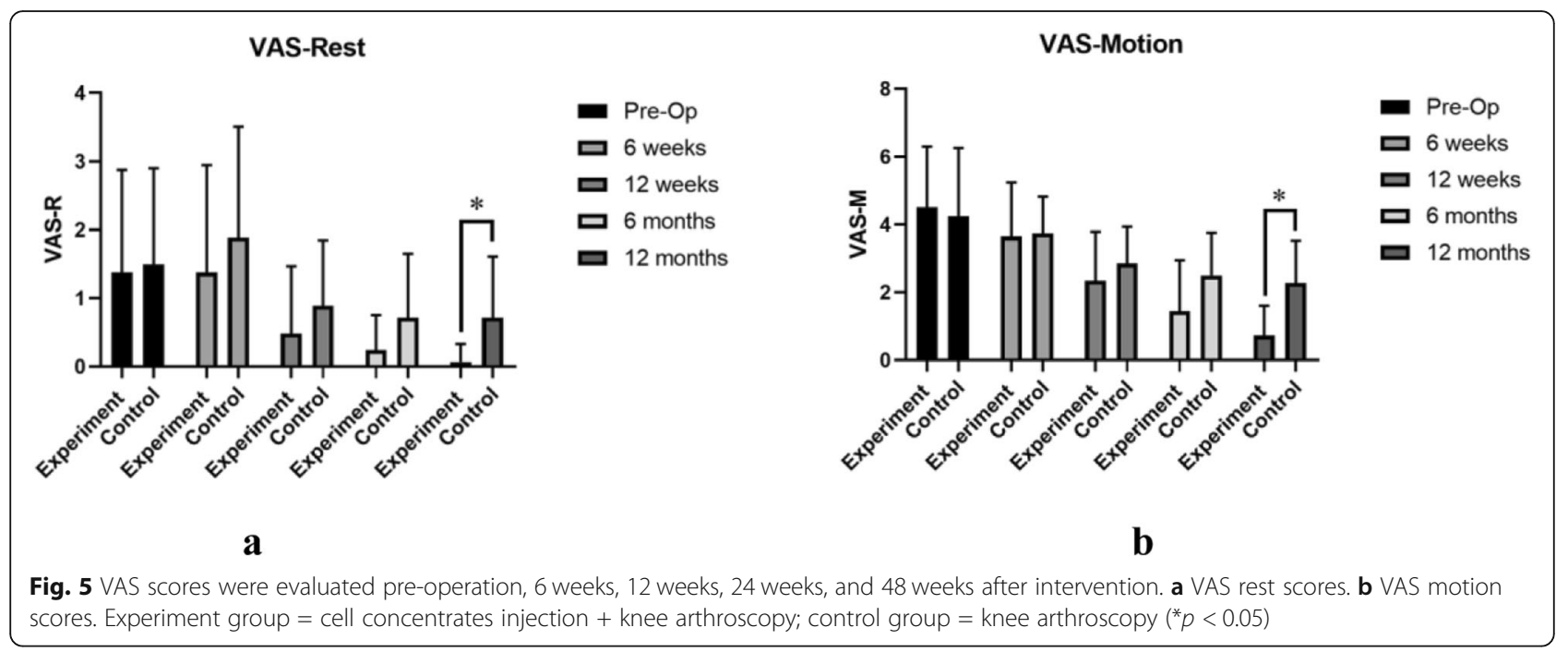

with the production of fibrous tissue or fibrocartilage [3]. Therefore, degeneration is likely to occur and can progress to osteoarthritic changes in many cases [25].

MSCs, such as bone marrow mesenchymal stromal cells (BMSCs), synovial-derived MSCs (SDMSCs), and adipose-derived MSCs (ADMSCs), can be extracted from different kinds of tissue, whereas only MSCs derived from bone marrow and adipose can be acquired in large amounts for clinical use [14-16, 26-29]. Compared with BMSCs, ADMSCs have a more active proliferative capacity, and their acquisition causes less damage to the donor zone $[24,30-32]$. Meanwhile, studies have also shown that MSCs from different kinds of tissues have significantly different proliferation and differentiation abilities. According to Zhang et al. [33], compared with MSCs derived from the synovium lining of the joint capsule and the synovium surrounding the cranial

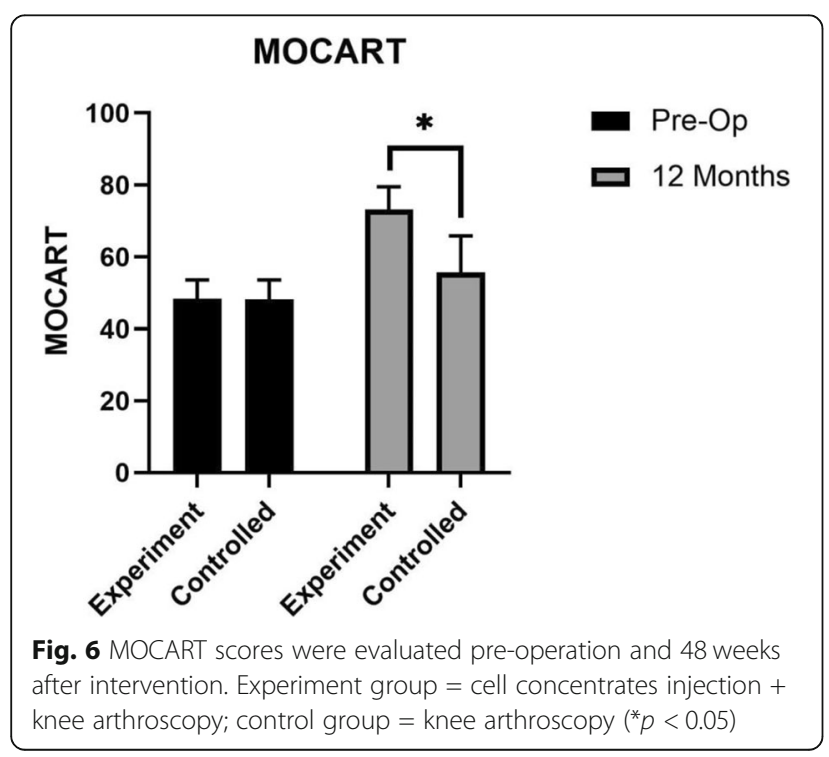

cruciate ligament, MSCs from the infrapatellar adipose tissue show a higher ability to proliferate and differentiate.

Recent studies suggest that the use of MSCs for treating knee cartilage lesions is a safe way to alleviate pain and improve knee function [34-36]. Toghraie et al. [37] used scaffold-free MSCs obtained from IPFPs in an experimental animal model of osteoarthritis by direct intra-articular injection. Rabbits receiving MSCs showed a lower degree of cartilage degeneration, osteophyte formation, and subchondral sclerosis than control group 20 weeks after surgery. According to a study by Liu et al. [38], it is possible to generate robust, flexible, cartilage-like grafts of scale, indicating that tissues engineered using IPFP-MSCs derived from osteoarthritis (OA) patients could potentially be used to resurface large joint areas damaged by trauma or disease. Skalska et al. [39] showed that MSCs derived from IPFP of rheumatoid arthritis (RA) patients have comparable or slightly stronger osteogenic potential than that from osteoarthritis patients. Koh et al. [40, 41] performed several stem cell injections combined with arthroscopic debridement in patients with knee OA. The short-term results demonstrated that IPFP-MSC therapy with intra-articular injections is safe, aids in reducing pain, and improves function in patients with knee OA. Compared to the in vivo studies mentioned above, our study provided a larger sample and a more controlled experimental design. In addition, MOCART scores were added to evaluate the repair of cartilage lesions, and flow cytometry was used to examine the positive rate of MSCs among the cell concentrates derived from IPFP through knee arthroscopy.

In our study, cell concentrates containing MSCs instead of pure stromal cells were injected into the knee 
Pre-Operation

\section{Experiment}

\section{Control}

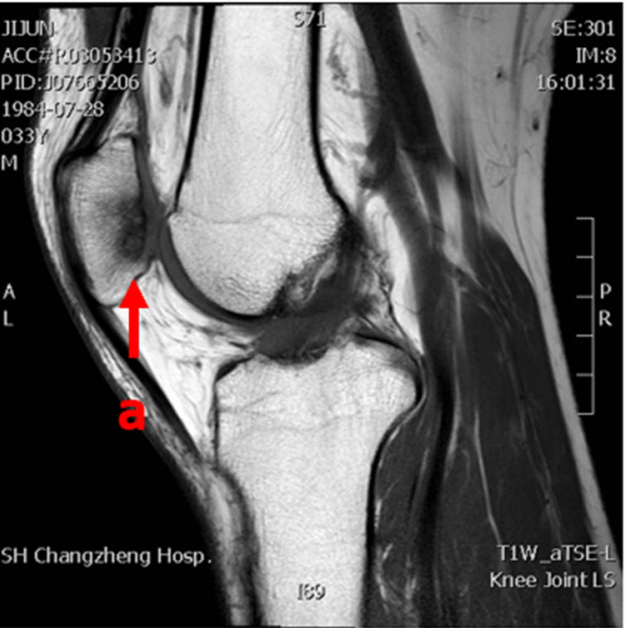

\section{Post-12months}
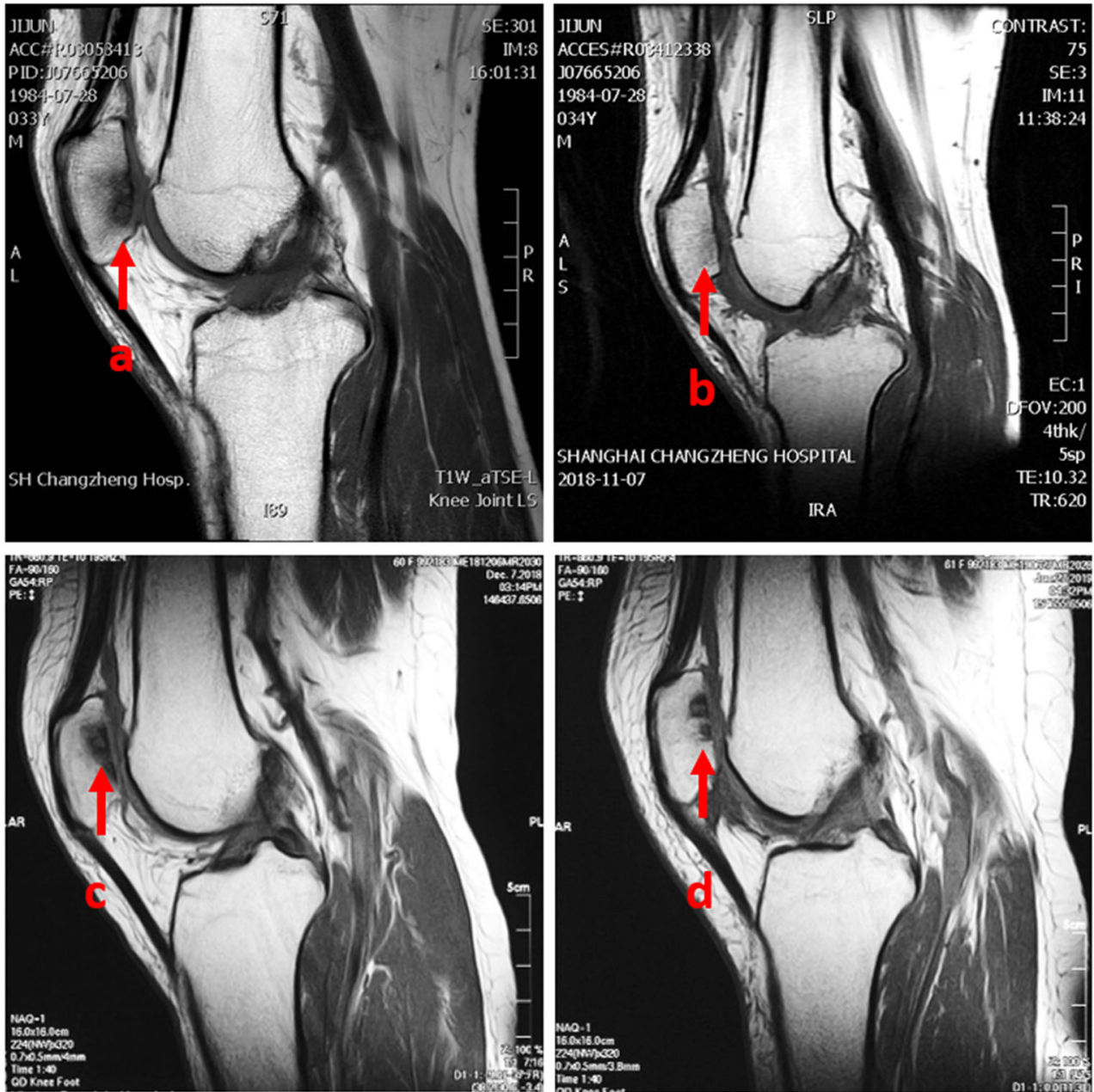

Fig. 7 Results of MRI performed preoperatively (a and $\mathbf{c}$ ) and 12 months postoperatively (b and $\mathbf{d}$ ) on two patients. The experiment group (a and $\mathbf{b}$ ) was a 30-year-old male with arthritis in patellofemoral joint. T1-weighted fast spin-echo sagittal view 12 months after surgery showed obvious cartilage reparation with the MOCART score of 80 . The control group (c and d) was a 38-year-old female with approximately same arthritis in patellofemoral joint. T1-weighted fast spin-echo sagittal view 12 months after surgery showed less cartilage reparation with the MOCART score of 55

cavity. Compared with obtaining pure stromal cells, the procedure to acquire cell concentrates can be simple and quick, thus, decreasing the operating time and reducing the risk of infection associated with injection. On the other hand, since cell concentrates were derived from IPFP abandoned during regular arthroscopy surgery, it is a way to recycle waste reducing the cost of surgery and increasing patients' compliance.

Instead of being cultured as in other studies, the cell concentrates containing MSCs were injected into the joint cavity directly during arthroscopy surgery. It is widely believed that culture microenvironment can affect the differentiation of MSCs [27, 28, 42-46], and the culturing process can add the risk of infection. According to the studies, it is known that the proliferation and differentiation of MSCs can be influenced by the paracrine effects of the cytokines and growth factors released by the grafted cells, which can trigger host-associated signaling pathways, increase angiogenesis, and decrease apoptosis. López-Ruiz et al. [47] showed that cells exposed to chondrocyte extracts acquire a characteristic morphological and ultrastructural chondrocyte phenotype, which was confirmed by the increased proteoglycan formation on enhanced collagen II immunostaining. Moreover, chondrocyte extracts induced an increase in mRNA expression of chondrogenic genes such as Sox9, L-Sox5, Sox6, and Col2a1.

According to the identification standards proposed by the International Society for Cellular Therapy (ISCT) in 2006, MSCs should meet the following standards: (1) cell 
Table 4 Outcome measures at pre-operation, 6 weeks, 12 weeks, 6 months, and 12 months

\begin{tabular}{|c|c|c|c|c|}
\hline Parameter & & Experiment group & Control group & $P$ values \\
\hline \multirow[t]{5}{*}{ WOMAC pain } & Pre-op & $4.83 \pm 2.94$ & $4.96 \pm 3.16$ & $>0.05$ \\
\hline & 6 weeks & $4.57 \pm 3.80$ & $5.6 \pm 4.24$ & $>0.05$ \\
\hline & 12 weeks & $3.10 \pm 2.95$ & $3.60 \pm 3.12$ & $>0.05$ \\
\hline & 6 months & $1.77 \pm 2.06$ & $2.83 \pm 2.09$ & $>0.05$ \\
\hline & 12 months & $1.00 \pm 1.26$ & $2.73 \pm 2.23$ & $<0.05$ \\
\hline \multirow[t]{5}{*}{ WOMAC stiffness } & Pre-op & $1.07 \pm 1.11$ & $1.33 \pm 1.49$ & $>0.05$ \\
\hline & 6 weeks & $1.80 \pm 1.40$ & $1.9 \pm 2.02$ & $>0.05$ \\
\hline & 12 weeks & $1.17 \pm 1.32$ & $1.2 \pm 1.19$ & $>0.05$ \\
\hline & 6 months & $0.87 \pm 1.14$ & $0.93 \pm 1.05$ & $>0.05$ \\
\hline & 12 months & $0.63 \pm 1.10$ & $0.86 \pm 0.94$ & $>0.05$ \\
\hline \multirow[t]{5}{*}{ WOMAC function } & Pre-op & $13.30 \pm 9.26$ & $13.73 \pm 11.97$ & $>0.05$ \\
\hline & 6 weeks & $15.93 \pm 13.81$ & $14.83 \pm 11.00$ & $>0.05$ \\
\hline & 12 weeks & $11.60 \pm 12.11$ & $12.7 \pm 10.19$ & $>0.05$ \\
\hline & 6 months & $6.70 \pm 6.96$ & $10.27 \pm 8.53$ & $<0.05$ \\
\hline & 12 months & $4.30 \pm 4.04$ & $10.13 \pm 8.82$ & $<0.05$ \\
\hline \multirow[t]{5}{*}{ WOMAC total } & Pre-op & $19.20 \pm 11.90$ & $19.90 \pm 14.19$ & $>0.05$ \\
\hline & 6 weeks & $22.30 \pm 17.67$ & $22.23 \pm 13.14$ & $>0.05$ \\
\hline & 12 weeks & $15.87 \pm 15.13$ & $17.43 \pm 12.05$ & $>0.05$ \\
\hline & 6 months & $9.33 \pm 9.44$ & $14.03 \pm 9.58$ & $<0.05$ \\
\hline & 12 months & $5.93 \pm 5.84$ & $13.73 \pm 9.85$ & $<0.05$ \\
\hline \multirow[t]{5}{*}{ VAS rest } & Pre-op & $1.40 \pm 1.48$ & $1.50 \pm 1.41$ & $>0.05$ \\
\hline & 6 weeks & $1.47 \pm 1.61$ & $1.93 \pm 1.57$ & $>0.05$ \\
\hline & 12 weeks & $0.53 \pm 1.01$ & $0.97 \pm 1.00$ & $>0.05$ \\
\hline & 6 months & $0.30 \pm 0.60$ & $0.77 \pm 0.94$ & $>0.05$ \\
\hline & 12 months & $0.10 \pm 0.30$ & $0.73 \pm 0.90$ & $<0.05$ \\
\hline \multirow[t]{5}{*}{ VAS motion } & Pre-op & $4.50 \pm 1.76$ & $4.43 \pm 2.13$ & $>0.05$ \\
\hline & 6 weeks & $3.70 \pm 1.58$ & $3.8 \pm 1.06$ & $>0.05$ \\
\hline & 12 weeks & $2.60 \pm 1.99$ & $2.83 \pm 1.05$ & $>0.05$ \\
\hline & 6 months & $1.67 \pm 1.90$ & $2.53 \pm 1.25$ & $>0.05$ \\
\hline & 12 months & $0.77 \pm 0.90$ & $2.3 \pm 1.21$ & $<0.05$ \\
\hline \multirow[t]{2}{*}{ MOCART } & Pre-op & $48.33 \pm 5.22$ & $48.17 \pm 5.68$ & $>0.05$ \\
\hline & 12 months & $73.45 \pm 6.28$ & $52.68 \pm 7.26$ & $<0.05$ \\
\hline
\end{tabular}

Data are presented as mean \pm SD

adhesion growth in vitro; (2) positive expression of CD44, CD73, CD90, and CD105 (positive detection rate of flow cytometry >95\%) and negative expression of CD11b, CD14, CD19, CD34, CD45, CD79 $\alpha$, and HLADR (the positive detection rate of flow cytometry $<2 \%$ ); and (3) having the capability to differentiate into osteoblasts, adipocytes, and cartilage cells in vitro in specific culture conditions [21].

It is shown that clinical effect of treating knee cartilage lesion with knee IPFP cell concentrates is positive. However, as the number of cells derived from the process is limited, this type of therapy is only suitable for small areas of cartilage lesions. According to a review by Richter et al. [48], small cartilage lesions (area $>2 \mathrm{~cm}^{2}$ ) are best treated by microfracture and cartilage autotransplantation. As for lesion areas between 2 and $4 \mathrm{~cm}^{2}$, cartilage autotransplantation and chondrocyte autotransplantation have similar therapeutic effect. For areas beyond $4 \mathrm{~cm}^{2}$, chondrocyte autotransplantation is the best choice. Although the clinical effect of treating knee cartilage lesions with knee IPFP cell concentrates is positive, randomized controlled trials with larger sample size and longer follow-up periods are still needed. So far, there are still several technical obstacles to overcome, such as finding a better method to extract, purify, and 
maintain multipotential differentiation, promote specificity and function, and enhance the survival and cartilage repair ability of IPFP-MSCs.

The present study has some limitations. First, the number of cells injected into each knee was limited and not equal among patients. Second, the patient sample size was small, and the follow-up period was relatively short. In addition, there were no data collected from routine second-look arthroscopic procedure or pathologic examination. In addition, we lost nearly $5 \%$ of our patients when these individuals refused to participate in some parts of the follow-up visits.

In the future, tissue-engineering techniques with cell concentrates containing MSCs hold promise for repairing damaged cartilage within joints. At present, although further randomized controlled clinical trials of this treatment, with more patients and longer follow-up periods, are still needed, this study proposes a new option for clinical treatment of knee cartilage lesions.

\section{Conclusions}

The short-term results of our study are encouraging and demonstrate that knee arthroscopy with IPFP cell concentrates containing MSCs is safe, while reducing pain and improving function in patients with knee cartilage lesions especially 6 months after surgery. Thus, the present study offers a new clinical approach and a series of data for further clinical trials.

\section{Abbreviations}

MSC: Mesenchymal stromal cells; IPFP: Infrapatellar fat pad; FBG: Fasting blood glucose; WOMAC: Western Ontario and McMaster Universities Osteoarthritis Index; VAS: Visual analog scale; MRI: Magnetic resonance imaging; MOCART: Magnetic Resonance Observation of Cartilage Repair Tissue; SAEs: Serious adverse events; OA: Osteoarthritis

\section{Acknowledgements}

We would like to thank the radiology department of Shanghai Changzheng Hospital, Naval Medical University, for their assistance with original image collection.

\section{Authors' contributions}

Q.Q., J.Z., and Y.C. equally contributed to the overall design of the project, execution of the study methods, construction of the manuscript, and approval of the submitted and final versions, and should be considered as co-corresponding authors. Y.Z., H.L., and D.X. equally contributed to the execution of the study methods and construction of the manuscript, and should be considered as co-first authors. J.S., Q.F., Y.H., and J.Z. oversaw the project overall and contributed to the execution of the study methods. All authors have read and approved the final submitted manuscript.

\section{Funding}

This study was supported by the National Key Research Development Plan (2017YFC1103404).

\section{Availability of data and materials}

The datasets generated and/or analyzed during the current study are not publicly available because it contains patients' personal information but are available from the corresponding author on reasonable request.

\section{Ethics approval and consent to participate}

The study conformed to the principles of the Declaration of Helsinki. The trial was endorsed by the Shanghai Changzheng Hospital Ethics Committee (CZEC (2016)-02), and written informed consent was obtained. The trial was registered (ChiCTR1800015379).

\section{Consent for publication}

Written informed consent for publication of their clinical details and/or clinical images were obtained from the patient/parent/guardian/relative of the patient.

\section{Competing interests}

The authors declare that they have no competing interests.

Received: 11 June 2020 Accepted: 11 January 2021

Published online: 28 January 2021

\section{References}

1. Paatela T, Vasara A, Nurmi H, Kautiainen H, Kiviranta I. Assessment of cartilage repair quality with the International Cartilage Repair Society score and the Oswestry Arthroscopy Score. J Orthop Res. 2020;38(3):555-62.

2. Piasecki DP, Spindler KP, Warren TA, Andrish JT, Parker RD. Intraarticular injuries associated with anterior cruciate ligament tear: findings at ligament reconstruction in high school and recreational athletes. An analysis of sexbased differences. Am J Sports Med. 2003;31(4):601-5.

3. Oldershaw RA. Cell sources for the regeneration of articular cartilage: the past, the horizon and the future. Int J Exp Pathol. 2012;93(6):389-400.

4. Simon LS. OARSI clinical trials recommendations: an abbreviated regulatory guide to the clinical requirements for development of therapeutics in osteoarthritis. Osteoarthr Cartil. 2015;23(5):674-6.

5. Brittberg M, Lindahl A, Nilsson A, Ohlsson C, Isaksson O, Peterson L. Treatment of deep cartilage defects in the knee with autologous chondrocyte transplantation. N Engl J Med. 1994;331(14):889-95.

6. Gao C, Seuntjens J, Kaufman GN, Tran-Khanh N, Butler A, Li A, et al. Mesenchymal stem cell transplantation to promote bone healing. J Orthop Res. 2012;30(8):1183-9.

7. Riyami M, Rolf $\mathrm{C}$. Evaluation of microfracture of traumatic chondral injuries to the knee in professional football and rugby players. J Orthop Surg Res. 2009;4:13.

8. Gomoll AH, Farr J, Gillogly SD, Kercher JS, Minas T. Surgical management of articular cartilage defects of the knee. Instr Course Lect. 2011;60:461-83.

9. Biant LC, MCNicholas MJ, Sprowson AP, Spalding T. The surgical management of symptomatic articular cartilage defects of the knee: consensus statements from United Kingdom knee surgeons. Knee. 2015; 22(5):446-9.

10. Wright JG. Autologous chondrocyte transplantation. N Engl J Med. 1995; 332(8):540.

11. Akkiraju $\mathrm{H}$, Nohe A. Role of chondrocytes in cartilage formation, progression of osteoarthritis and cartilage regeneration. J Dev Biol. 2015;3(4):177-92.

12. Zuk PA, Zhu M, Mizuno H, Huang J, Futrell JW, Katz AJ, et al. Multilineage cells from human adipose tissue: implications for cell-based therapies. Tissue Eng. 2001;7(2):211-28.

13. Mohanraj B, Huang AH, Yeger-McKeever MJ, Schmidt MJ, Dodge GR, Mauck RL. Chondrocyte and mesenchymal stem cell derived engineered cartilage exhibits differential sensitivity to pro-inflammatory cytokines. J Orthop Res. 2018;36(11):2901-10.

14. Filardo G, Perdisa F, Roffi A, Marcacci M, Kon E. Stem cells in articular cartilage regeneration. J Orthop Surg Res. 2016;11:42.

15. Ronziere MC, Perrier E, Mallein-Gerin F, Freyria AM. Chondrogenic potential of bone marrow- and adipose tissue-derived adult human mesenchymal stem cells. Biomed Mater Eng. 2010;20(3):145-58.

16. English A, Jones EA, Corscadden D, Henshaw K, Chapman T, Emery P, et al. A comparative assessment of cartilage and joint fat pad as a potential source of cells for autologous therapy development in knee osteoarthritis. Rheumatology (Oxford). 2007:46(11):1676-83.

17. Wickham MQ, Erickson GR, Gimble JM, Vail TP, Guilak F. Multipotent stromal cells derived from the infrapatellar fat pad of the knee. Clin Orthop Relat Res. 2003:412:196-212.

18. Tangchitphisut $P$, Srikaew N, Numhom S, Tangprasittipap A, Woratanarat $P$, Wongsak $\mathrm{S}$, et al. Infrapatellar fat pad: an alternative source of adiposederived mesenchymal stem cells. Arthritis. 2016;2016:4019873. 
19. Pizzute T, Zhang Y, He F, Pei M. Ascorbate-dependent impact on cellderived matrix in modulation of stiffness and rejuvenation of infrapatellar fat derived stem cells toward chondrogenesis. Biomed Mater. 2016;11(4): 045009 .

20. Fossett E, Khan WS, Longo UG, Smitham PJ. Effect of age and gender on cell proliferation and cell surface characterization of synovial fat pad derived mesenchymal stem cells. J Orthop Res. 2012;30(7):1013-8.

21. Dominici M, Le Blanc K, Mueller I, Slaper-Cortenbach I, Marini F, Krause D, et al. Minimal criteria for defining multipotent mesenchymal stromal cells. The International Society for Cellular Therapy position statement. Cytotherapy. 2006;8(4):315-7.

22. Lapuente JP, Dos-Anjos S, Blazquez-Martinez A. Intra-articular infiltration of adipose-derived stromal vascular fraction cells slows the clinical progression of moderate-severe knee osteoarthritis: hypothesis on the regulatory role of intra-articular adipose tissue. J Orthop Surg Res. 2020;15(1):137.

23. Dragoo JL, Chang W. Arthroscopic harvest of adipose-derived mesenchymal stem cells from the infrapatellar fat pad. Am J Sports Med. 2017;45(13): 3119-27.

24. Salyutin RV, Zapohlska KM, Palyanytsya SS, Sirman VM, Sokolov MF Differentiation of mesenchymal stem cells of adipose tissue. Klin Khir. 2015; 3:61-4.

25. Shelbourne KD, Jari S, Gray T. Outcome of untreated traumatic articular cartilage defects of the knee: a natural history study. J Bone Joint Surg Am. 2003;85-A(Suppl 2):8-16.

26. Li $X$, Wang $M$, Jing $X$, Guo W, Hao C, Zhang Y, et al. Bone marrow- and adipose tissue-derived mesenchymal stem cells: characterization, differentiation, and applications in cartilage tissue engineering. Crit Rev Eukaryot Gene Expr. 2018;28(4):285-310.

27. Arora A, Sriram M, Kothari A, Katti DS. Co-culture of infrapatellar fat padderived mesenchymal stromal cells and articular chondrocytes in plasma clot for cartilage tissue engineering. Cytotherapy. 2017;19(7):881-94.

28. Wu J, Kuang L, Chen C, Yang J, Zeng WN, Li T, et al. miR-100-5p-abundant exosomes derived from infrapatellar fat pad MSCs protect articular cartilage and ameliorate gait abnormalities via inhibition of mTOR in osteoarthritis. Biomaterials. 2019;206:87-100.

29. Dilogo $\mathrm{IH}$, Mujadid F, Nurhayati RW, Kurniawan A. Evaluation of bone marrow-derived mesenchymal stem cell quality from patients with congenital pseudoarthrosis of the tibia. J Orthop Surg Res. 2018;13(1):266.

30. Luo L, Thorpe SD, Buckley CT, Kelly DJ. The effects of dynamic compression on the development of cartilage grafts engineered using bone marrow and infrapatellar fat pad derived stem cells. Biomed Mater. 2015;10(5):055011.

31. Ding DC, Wu KC, Chou HL, Hung WT, Liu HW, Chu TY. Human infrapatellar fat pad-derived stromal cells have more potent differentiation capacity than other mesenchymal cells and can be enhanced by hyaluronan. Cell Transplant. 2015;24(7):1221-32.

32. Kisiday JD, Lee CM, Mcllwraith CW, Frisbie DD. Induction of bone marrow mesenchymal stem cell chondrogenesis following short-term suspension culture. J Orthop Res. 2011;29(1):26-32.

33. Zhang N, Dietrich MA, Lopez MJ. Canine intra-articular multipotent stromal cells (MSC) from adipose tissue have the highest in vitro expansion rates, multipotentiality, and MSC immunophenotypes. Vet Surg. 2013;42(2):137-46.

34. Chen WH, Lin CM, Huang CF, Hsu WC, Lee CH, Ou KL, et al. Functional recovery in osteoarthritic chondrocytes through hyaluronic acid and platelet-rich plasma-inhibited infrapatellar fat pad adipocytes. Am J Sports Med. 2016:44(10):2696-705

35. Almeida HV, Eswaramoorthy R, Cunniffe GM, Buckley CT, O'Brien FJ, Kelly DJ. Fibrin hydrogels functionalized with cartilage extracellular matrix and incorporating freshly isolated stromal cells as an injectable for cartilage regeneration. Acta Biomater. 2016;36:55-62.

36. Prabhakar A, Lynch AP, Ahearne M. Self-assembled infrapatellar fat-pad progenitor cells on a poly-epsilon-caprolactone film for cartilage regeneration. Artif Organs. 2016;40(4):376-84.

37. Toghraie FS, Chenari N, Gholipour MA, Faghih Z, Torabinejad S, Dehghani S, et al. Treatment of osteoarthritis with infrapatellar fat pad derived mesenchymal stem cells in Rabbit. Knee. 2011;18(2):71-5.

38. Liu Y, Buckley CT, Almeida HV, Mulhall KJ, Kelly DJ. Infrapatellar fat padderived stem cells maintain their chondrogenic capacity in disease and can be used to engineer cartilaginous grafts of clinically relevant dimensions. Tissue Eng Part A. 2014;20(21-22):3050-62.

39. Skalska U, Kontny E. Adipose-derived mesenchymal stem cells from infrapatellar fat pad of patients with rheumatoid arthritis and osteoarthritis have comparable immunomodulatory properties. Autoimmunity. 2016;49(2): 124-31.

40. Koh YG, Choi YJ. Infrapatellar fat pad-derived mesenchymal stem cell therapy for knee osteoarthritis. Knee. 2012;19(6):902-7.

41. Koh YG, Jo SB, Kwon OR, Suh DS, Lee SW, Park SH, et al. Mesenchymal stem cell injections improve symptoms of knee osteoarthritis. Arthroscopy. 2013; 29(4):748-55.

42. Cassiede P, Dennis JE, Ma F, Caplan Al. Osteochondrogenic potential of marrow mesenchymal progenitor cells exposed to TGF-beta 1 or PDGF-BB as assayed in vivo and in vitro. J Bone Miner Res. 1996;11(9):1264-73.

43. Carter DR, Beaupré GS, Giori NJ, Helms JA. Mechanobiology of skeletal regeneration. Clin Orthop Relat Res. 1998;(355 Suppl):S41-55. https://doi. org/10.1097/00003086-199810001-00006.

44. Cui JH, Park K, Park SR, Min BH. Effects of low-intensity ultrasound on chondrogenic differentiation of mesenchymal stem cells embedded in polyglycolic acid: an in vivo study. Tissue Eng. 2006;12(1):75-82.

45. Fan L, Chen J, Tao Y, Heng BC, Yu J, Yang Z, et al. Enhancement of the chondrogenic differentiation of mesenchymal stem cells and cartilage repair by ghrelin. J Orthop Res. 2019;37(6):1387-97.

46. Aikawa J, Uchida K, Takano S, Inoue G, Minatani A, Miyagi M, et al. Expression of calcitonin gene-related peptide in the infrapatellar fat pad in knee osteoarthritis patients. J Orthop Surg Res. 2017;12(1):65.

47. Lopez-Ruiz E, Peran M, Cobo-Molinos J, Jimenez G, Picon M, Bustamante M, et al. Chondrocytes extract from patients with osteoarthritis induces chondrogenesis in infrapatellar fat pad-derived stem cells. Osteoarthr Cartil. 2013;21(1):246-58

48. Richter DL, Schenck RC Jr, Wascher DC, Treme G. Knee articular cartilage repair and restoration techniques: a review of the literature. Sports Health. 2016;8(2):153-60.

\section{Publisher's Note}

Springer Nature remains neutral with regard to jurisdictional claims in published maps and institutional affiliations.
Ready to submit your research? Choose BMC and benefit from:

- fast, convenient online submission

- thorough peer review by experienced researchers in your field

- rapid publication on acceptance

- support for research data, including large and complex data types

- gold Open Access which fosters wider collaboration and increased citations

- maximum visibility for your research: over $100 \mathrm{M}$ website views per year

At $\mathrm{BMC}$, research is always in progress.

Learn more biomedcentral.com/submissions 